\title{
SECULARIZACIÓN INTERMINABLE Y GANANCIA INCITATIVA EN UN ENCUENTRO ENTRE RELIGIÓN Y POLÍTICA ${ }^{1}$
}

\section{ENDLESS SECULARIZATION AND INCITEMENT GAIN BETWEEN RELIGION AND POLITICS}

\author{
Javier Tapia Balladares*
}

RESUMEN

En este artículo ${ }^{2}$ se discuten las condiciones psicosociales y psicoreligiosas que han permitido la irrupción de un grupo político en la vida social y política costarricense a partir del año 2018. Esto se hace sin dejar de examinar los escenarios psicosociales que se abren a partir de la irrupción de un grupo político inusual, hasta ahora, en la sociedad costarricense. Se hace una lectura analítica e interpretativa tratando de añadir argumentos a favor de la hipótesis de la desigualdad. Para discutir dicha hipótesis se siguen las ideas de reconocimiento de los movimientos religiosos libres, la inclusión del otro y la articulación subjetiva y socioafectiva que puede ser promovida por una democracia incitativa. La incitación se opondría a la autocomplacencia institucional que ignora a los grupos más desfavorecidos por la desigualdad.

PALABRAS CLAVE: RELIGIÓN * POLÍTICA * INCITACIÓN * RECONOCIMIENTO * PSICOLOGÍA SOCIAL

\section{ABSTRACT}

This article discusses the psychosocial and the psychoreligious conditions that have allowed the emergence of a religious group in Costa Rica's social and political life since 2018. This is done while considering the psychosocial scenarios that emerged from the appearance of an unusual political group, so far, in the Costa Rican society. An analytical and interpretative reading is done trying to add arguments in favour of the inequality hypothesis. To discuss this hypothesis, we follow the ideas of recognition of free religious movements, the inclusion of the other and the subjective and socioaffective articulation

$1 \quad$ El autor declara que no posee conflictos de interés relacionados con la publicación de este artículo. No recibió fondos para su realización, sin embargo, este fue elaborado como parte de su trabajo como profesor e investigador de la Universidad de Costa Rica.

* Escuela de Psicología de la Universidad de Costa Rica, Costa Rica. Javier.tapiaballadares@ucr.ac.cr

2 Se agradece la lectura crítica y los comentarios muy atinados a una versión preliminar del manuscrito, realizada por el Dr. Carlos Brenes Peralta del Centro de Investigación y Estudios Políticos de la Universidad de Costa Rica. 
that can be promoted by an inciting democracy. Incitement would oppose the institutional complacency that ignores the most disadvantaged groups, products of inequality.

KEYWORDS: RELIGION * POLITICS * INCITING * RECOGNITION * SOCIAL PSYCHOLOGY

\section{INTRODUCCIÓN}

Un seísmo político inesperado sobrevino en la Costa Rica de 2018; no por haber elegido a los diputados de su Asamblea Legislativa, ni por haber elegido al presidente cuarenta $y$ ocho de la segunda república de este pequeño país centroamericano. Una larga trayectoria de procesos electorales y transiciones democráticas precedían estas elecciones. Hacia la segunda mitad del siglo xx y al iniciar el siglo xxI, dichos procesos electorales habían estado marcados por la influencia de dos partidos políticos: el Partido Liberación Nacional y el Partido Unidad Social Cristiana. Si bien, en el momento de su fundación estos grupos políticos podían identificarse, desde el punto de vista ideológico, con una cierta visión de la socialdemocracia y con una cierta apropiación de los principios demócrata cristianos, con el tiempo, aunque también bajo la influencia de los procesos económicos internacionales, al enfatizar ambos en una visión económica liberal, sus diferencias se fueron desdibujando.

Esos dos partidos políticos también se desdibujaron como organizaciones electorales (por la corrupción) y en su capacidad de proponer un proyecto de país (por la carencia de propuestas convincentes). Esto ya había quedado en evidencia en las elecciones de 2014 con el acceso al control del gobierno por el Partido Acción Ciudadana (Treminio, 2018). Por ejemplo, el Partido Liberación Nacional obtuvo el 35,6\% de las simpatías políticas en el 2007, mientras que en el año 2015, obtuvo solamente el 20\% de dichas simpatías. El Partido Unidad Social Cristiana descendió en la atracción de simpatías políticas entre el electorado del 10,1\% en 2007 al 6,3\% en el 2015 (Pignataro y Cascante, 2017).

En 2018, el proceso político-electoral se configuró de manera un poco diferente. Aunque en elecciones anteriores los partidos confesionales habían logrado representaciones minoritarias en la Asamblea Legislativa, no fue hasta el 2018 cuando se convirtieron en fuerza electoral en el parlamento, sino como alternativa con posibilidades de ser electos en el poder ejecutivo. En efecto, el surgimiento de un partido confesional, orientado por un credo cristiano neo-pentecostal con algunas características fundamentalistas, adquirió una gran fuerza electoral. Esto representó casi un seísmo en una sociedad poco habituada a estos movimientos políticos, lo cual se vio reflejado en el candidato del Partido Restauración Nacional, quien pudo aspirar seriamente a la presidencia de la república, la cual no obtuvo. Este hecho no solo ha debilitado la presencia de los dos partidos políticos tradicionales, ya transformada desde antes de 2014 en un contexto de fragmentación política (Pignataro y Cascante, 2017; AlfaroRedondo y Gómez-Campos, 2014), sino que, en alguna medida, facilitó un nuevo gobierno del Partido Acción Ciudadana. Aunque también ha representado una irrupción, aparentemente inesperada, en la vida política costarricense.

Así, entonces, tras la primera vuelta electoral del 2018, se volvió relevante la pregunta ¿Qué nos pasó? (Murillo, 07/02/2018), la cual dejaba la estela de un cuestionamiento sobre la Costa Rica de las transiciones democráticas y de menor desigualdad socioeconómica y cultural, con un bajo nivel de confrontación ideológica. Planteaba, además, el cuestionamiento provocado por el efecto sorpresa, sobre quién es quién realmente en la sociedad costarricense, sobre su composición, sobre cómo se transformó esta sociedad, quizás sin percatarse de ello lo suficiente, desde la adhesión a valores e ideales tradicionales hacia una visión axiológica postradicional digital, es decir, el comienzo de una articulación axiológica sobre 
nuevos valores, aún en construcción, con una relativa ruptura de la tradición y marcada de manera significativa por la era digital (Tapia, 2019). Esto ocurre sin ser todavía una sociedad completamente laica $y$ en transición hacia la modernidad cultural y la modernización económica. La pregunta implicaba aceptar que un partido político confesional había movilizado la percepción colectiva de la vida social y de las representaciones culturales; la cuestión se jugaba más allá del proceso político en sí mismo. Simultáneamente, implica que la comprensión del fenómeno requiere un ensanchamiento conceptual y reclama la mirada de otras disciplinas de las ciencias sociales como la Psicología y la Antropología, así como considerar la contribución de la Sociología (Fuentes, 2019).

En este ensayo científico social, teórico y analítico, se parte de una pregunta y se plantea una argumentación para darle posibles respuestas. Como tal, este artículo no aporta evidencias empíricas propias, primarias, sino que se utlizan fuentes de datos secundarias, evidencias empíricas ya disponibles, para acompañar los argumentos propuestos con la intención de darles más fuerza o ilustrarlos.

La pregunta que orienta las reflexiones analíticas en este artículo es ¿por qué nos pasó lo que nos pasó? En un sentido conceptual más específico, la pregunta es: ¿cuáles podrían ser las condiciones psicosociales y psicoreligiosas que han permitido la irrupción de un grupo religioso en la vida social y política? Además, ¿cuáles son los escenarios psicosociales que se abren a partir de la irrupción de un grupo político inusual en la sociedad costarricense?

Hasta ahora, las preguntas anteriores han tratado de responderse a partir de la hipótesis sociopolítica de las dos (o muchas) Costa Rica (ver Murillo, 07/02/2018 y Alpízar, 07/02/2018). Esta hipótesis — de la desigualdad- explicaría que en el país hay dos grandes grupos sociales que se constituyen como electores. Por un lado, el sector de la población que disfruta de la inclusión social, quienes obtienen más provecho de los beneficios educativos, económicos y sociales, generados por la dinámica socioeconómica y por las políticas estatales. Por otro lado, está la población más vulnerada y marginada, habitantes de las costas $y$ de las periferias urbanas $y$ rurales al interior del país, que no se beneficia de las escasas políticas públicas que se dirigen a beneficiar ese grupo, el cual no puede o no logra aprovechar las ventajas de la dinámica socioeconómica. Este último grupo de electores le habría dado la espalda a los actores de la política tradicional, que les ha dejado en la indiferencia social y en la marginalidad socioeconómica. Por ejemplo, en las elecciones de 2002, en las zonas rurales (centrales y marginales) hubo un $40,8 \%$ de personas abstencionistas, contra el 41,1\% del Gran Área Metropolitana (GAM). En las elecciones de 2006, hubo un 47,9\% de personas abstencionistas en las zonas rurales, contra un $35,1 \%$ en la GAM (Raventós, Fournier, Fernández y Alfaro, 2012). El Estado de la Nación, en sus análisis sobre la educación costarricense permite darle consistencia empírica a esa hipótesis. Lo que se ha llamado las dos Costa Rica ha estado ahí en los datos sobre educación, en la exclusión y deserción escolar, con buena cobertura, pero con baja calidad, en la falta de capacidad del Estado para revertir la realidad educativa en los márgenes del país; en sus márgenes geográficos, sociales y simbólicos (Programa Estado de la Nación en Desarrollo Humano Sostenible, 2017).

Este artículo busca hacer una lectura analítica e interpretativa, tratando de añadir argumentos a favor de la hipótesis anterior. Los argumentos estarán planteados desde la psicología de la religión y la filosofía social, buscando contribuir a la teoría social al enfocar procesos subjetivos y procesos sociales generales, en los que se basan su lógica y su dinámica. Es decir, sobre por qué un sector de la población emerge en la esfera pública de lo político, bajo el hábito de una confesión religiosa específica.

La ruta que se seguirá para mostrar esta lectura consiste en dialogar, en primer lugar, con la controversial teoría sociológica de la secularización para explicar la presencia y "resurgimiento" de la religión en la vida social y política, con el auxilio de algunos elementos de la filosofía social. Luego, tomando en consideración algunos datos reveladores sobre los 
resultados electorales recientes, será posible analizar, y a partir del diálogo con la teoría de la secularización, el significado psicosocial y psicoreligioso de esos resultados. Esto facilitará después extender ese significado al realizar una conexión con hallazgos y categorías propios de la discusión en psicología de la religión. Esta última aproximación permite introducir los aspectos subjetivos en el contexto de este análisis. Sin embargo, la lectura psicosocial y psicoreligiosa queda incompleta si no se extrae su potencial aporte al desarrollo de la vida en sociedad. A esta cuestión se dedican las reflexiones finales presentadas.

\section{MÁS ALLÁ DE LA SECULARIZACIÓN}

La teoría de la secularización implica el abandono progresivo de las confesiones religiosas a favor de la laicidad y la racionalidad, conforme avanza la industrialización y se aumenta el nivel educativo de la población; y se suele entender por laicidad un principio y un estado de cosas sociopolítico en el cual hay una separación en el ejercicio de las funciones del Estado respecto de la religión (clero) como institución (ver discusión sobre laicidad de Gaytán, 2018 y Gauchet, 1998). Al menos esta ha sido la explicación estándar que, en una buena medi$\mathrm{da}$, ha buscado dar cuenta de ese proceso, principalmente en Europa. En América Latina, por ejemplo, se tiende a coincidir en que el proceso de secularización es resultado de la modernización económica y cultural (Simbaña, 2016). La perspectiva de Tschannen que propone la secularización como paradigma y no como teoría (Beltrán, 2009), podría suponer el rechazo a la comprobación empírica del fenómeno de la secularización. Frente a esta posibilidad, resulta preferible el punto de vista de la psicología social (Hayward y Krause, 2014), que buscará la contrastación empírica a partir de microteorías que se desprendan de una concepción amplia de la secularización.

Hervieu-Léger (1999) ha planteado cuatro características de la modernidad que han conducido a la secularización, así como plantea el lado inverso de dichas características. En primer lugar, que la modernidad antepone, en todos los dominios de la acción, la racionalidad, es decir, la adaptación coherente de los medios a los fines. Significa que todas las personas obtienen su estatus social a partir solamente de sus competencias, adquiridas por la educación y la formación, y que la explicación del mundo físico, social y subjetivo depende solamente de enunciados precisos provenientes del pensamiento científico. Claro está que esto es más una aspiración que una realidad, debido a que tanto las decisiones económicas como los procesos científicos han mostrado su irracionalidad. En segundo lugar, la modernidad supone la autonomía del individuo, uno que es capaz de construir el mundo en que vive $y$ construir las significaciones que le dan sentido a su existencia. El revés de esta característica es que muchas sociedades subsisten bajo un código global de sentido que hace depender al individuo de la tradición y donde entonces la autonomía es relativa. En tercer lugar, la modernidad implica un tipo de organización social caracterizada por la diferenciación de las instituciones: lo político, lo religioso, lo económico, lo doméstico, el arte, la ciencia y la moral son ámbitos distintos de creación humana. Son dominios con reglas propias, pero con autonomía relativa, pues los dominios tienen entre sí relaciones diversas. En su realización histórica, las organizaciones sociales conocen una dinámica de cambio de avances y retrocesos, pero en todo caso de emancipación de la tutela de la religión.

Así entonces, la cuestión decisiva no se juega en la neta separación de racionalidad e irracionalidad o de ámbitos de la organización social, ni siquiera en la cuestión de la autonomía y la dependencia, en la medida que, cada una de estas polaridades aparece plenamente imbricada con la otra. De ahí que Hervieu-Léger (1999) apuesta por una comprensión de la secularización no como la pérdida de la religión en el mundo moderno, no como la desaparición de la religión en las sociedades secularizadas, sino como el conjunto de procesos de reconstrucción de las creencias que se producen en la sociedad moderna, cuyo motor es la insatisfacción de las expectativas que suscita esta y cuya condición cotidiana es la incertidumbre, enlazada a la búsqueda interminable de medios para satisfacer aquellas expectativas. Esta delimitación de la 
secularización no necesariamente se presenta en las sociedades latinoamericanas, pero define unos contornos $y$ unas tendencias semejantes en virtud de las similitudes y diferencias histórico-culturales.

Que la secularización es reconstrucción y transmutación constante de las creencias se ha observado de manera pertinaz en el cristianismo de Occidente y según observa la sociología de la religión, tanto en Europa como en América Latina. Tales creencias han dado muestras de una enorme capacidad de transformación o de adaptación a las exigencias de la modernidad. Es lo que sucedió en los años 60 del siglo pasado, con el Concilio Vaticano II dentro del catolicismo y es lo que podría estar sucediendo con el papado actual. De esta manera pueden identificarse ciclos de transformación y adaptación del cristianismo conforme acontecen diferentes cambios históricos. Ahora bien, aun cuando en Europa la religión perdió completamente su función articuladora de la vida política y del Estado, la discusión sobre si en Europa la gente ha dejado o no sus adhesiones religiosas como una experiencia personal, social y cultural todavía continúa, a pesar de su avanzada industrialización y sus altos niveles educativos en cobertura y calidad (Bermejo, 2013 y Cortina, 2013). De ahí que en Europa no se trata de una dinámica de retorno de lo religioso, sino de la lógica de transmutación constante de las creencias y del carácter paradójico de las relaciones de la modernidad con el cristianismo, en parte por su mutua imbricación histórico-cultural y representacional (HervieuLéger, 1999; Gauchet, 2004 y Gutiérrez, 2010).

En el caso del protestantismo en América Latina, el proceso secularizador y de cambio social tiene particularidades sociohistóricas (Bastian, 2006), distintas al catolicismo, más arraigado a los valores de la colonia. El protestantismo poseería un origen más comprometido con la posibilidad de creación de una república, incluso laica. Orígenes perdidos, que la investigación empírica reciente ya no descubre en el protestantismo pentecostal ni en los movimientos religiosos libres. El protestantismo pentecostal, fundamentalista o no, es para Bastian (2006), un producto híbrido de la efervescencia emocional $y$ de la modernidad, en lo que constituye un esfuerzo de adaptación al contexto latinoamericano y esto pese a la reticencia de las élites. Bastian señala también el caso específico de Centroamérica, donde el protestantismo pentecostal expresa una fuerte conexión con la cultura popular. Es decir, que el proceso de secularización desde el punto de vista del cristianismo protestante, expresa una serie de mutaciones específicas, las cuales no escapan tampoco a una mutua imbricación histórico-cultural y representacional. Ahora bien, cabe hacer notar que el punto de vista de Bastian (2006), según el cual el pentecostalismo tiene un origen mejor conectado con las aspiraciones de la modernidad, es radicalmente opuesto al punto de vista de Armstrong (2004), quien vincula tales orígenes a un impulso fundamentalista que buscó oponerse incluso a la revolución que permitió la fundación de los Estados Unidos. De cualquier modo, son todos estos procesos de cambio propios de la modernización de los cuales no han quedado excluidas las creencias.

Si bien es cierto, la modernización económica y cultural ha sido parte de los cambios sociales de la Costa Rica del siglo xx, la secularización y el efecto de cambio que puede producir al interior de grupos y personas ha implicado un abandono solo relativo del cristianismo católico. Estos cambios, sin embargo, no representan todavía una salida del catolicismo y una entrada a la laicidad, sino que indica una dinámica con un doble valor: por un lado, a una nueva adhesión religioso-espiritual a una creencia o visión de mundo, a un conjunto de convicciones en los movimientos religiosos libres (MRL) y, por otro lado, simultáneamente, indica una transición más clara de la sociedad costarricense hacia los valores de la modernidad $y$ de la laicidad, transición que puede ser dolorosa y no desprovista de tensiones para algunos grupos, pero por dolorosa consiste en un aprendizaje colectivo. Esto forma parte de la dinámica de transformación de las creencias en el contexto de secularización (Hervieu-Léger y Davie, 2010).

Ahora bien, en realidad no se trata de una "salida" como se saldría de una sociedad 
tradicional para "entrar" después en una sociedad post-tradicional moderna, sin ningún retorno. Los ciclos hacen pensar que las metáforas de salir y entrar quedan superadas por otras, como quizás una metáfora gráfica como la de una elipsis vertical, la cual produce nuevas expresiones religioso-espirituales, con arraigo social, no solo vitales y simbólicas, sino también con impactos institucionales. En la lógica de la transformación constante de lo religioso, la secularización es un proceso interminable e indeterminado. Estos procesos de cambio no provienen exclusivamente de los cambios poblacionales o solo de la dinámica de los partidos políticos, sino también de procesos culturales y psicológicos o subjetivos, tanto por la forma en que las personas piensan al tomar decisiones, como por la forma en que las personas sienten cuando piensan en lo que les afecta.

Así pues, recuperando en este punto las preguntas planteadas, por un lado, sobre las condiciones psicosociales y psicoreligiosas que han permitido la irrupción de un grupo religioso en la vida social y política, por otro lado, sobre cuáles podrían ser los escenarios psicosociales que se abren a partir de la irrupción de un grupo político inusual en la sociedad costarricense, cabe indicar que, en buena medida, la respuesta se relaciona con asumir que en la modernidad hay una transmutación constante de las creencias. Este es un fenómeno sociocultural que forma parte de la trayectoria de cambios de la sociedad costarricense. De ello forma parte la migración de un sector importante de la población del cristianismo católico al cristianismo evangélico. Hay condiciones psicosociales y psicoreligiosas específicas que acompañan ese cambio. Lo más interesante es que ocurren simultáneamente con el interés potencial por las condiciones de la laicidad, por ejemplo, en las manifestaciones de una espiritualidad sin religión (Tapia, Rojas y Villalobos, 2013).

\section{¿QUIÉN SE ADJUDICÓ LAS ELECCIONES EN LA COSTA RICA DE 2018?}

Si a finales del siglo xx el cristianismo católico agrupaba a poco más del $90 \%$ de la población, en los últimos 30 a 40 años solo agrupa a un $60 \%$, quizás menos, dependiendo de los datos que se examinen. Un análisis histórico de diferentes encuestas sociodemográficas (Fuentes, 2015), mostraría cómo un importante sector de la población ha venido transformando su confesión para adherirse, no al cristianismo protestante histórico, ni al agnosticismo, ni al ateísmo, ni a otras religiones como el budismo o el islam, sino al cristianismo evangélico, incluyendo principalmente como tendencia predominante la adhesión a lo que se conoce como movimientos religiosos libres (MRL).

Es cierto que un partido político como Restauración Nacional, el cual se asocia a los movimientos religiosos libres, no fue el que se impuso en las elecciones de 2018. Según podría interpretarse a partir de los datos producidos por el Centro de Investigación y Estudios Políticos de la Universidad de Costa Rica (Alfaro, Alpízar, Cascante y Guzmán, enero de 2018), se impuso un candidato imaginario, encarnado por Carlos Alvarado, el cual cohesionó, por un lado, a los sectores no religiosos, presos del horror vacui que anunciaba el aniquilamiento potencial de las instituciones democráticas y de la racionalidad moderna, $y$ por otro lado, cohesionó Carlos Alvarado a los sectores religiosos del cristianismo católico, los cuales sintieron amenazado un símbolo fundamental de la identidad religiosa nacional como es La Negrita de los Ángeles, una advocación de la virgen María en el país (Ver especialmente pp. 12-16, en Alfaro, Alpízar, Cascante y Guzmán, abril de 2018). Sin embargo, que no se impusiera Restauración Nacional, no significa que, como actor político, dejara de obtener beneficios y perdiera la representación completa de una buena parte de lo que sería su base popular, a saber, los movimientos religiosos libres.

Entre las características que definen a los MRL, pueden mencionarse la extrema libertad en la interpretación de los textos bíblicos (en realidad no cuentan con una teología sistemática), la carencia de regulación por medio de normas institucionalizadas más allá del grupo local, y el alejamiento de y renuncia a la sociedad y sus normas. Algunos de esos grupos son los pentecostales, los neopentecostales $y$ otros grupos similares que profesan valores tradicionales, pero que no son 
necesariamente fundamentalistas, los cuales reúnen a una proporción de la población que ha ido transformando sus creencias, sus visiones de mundo o su ideología (Fuentes, 2015).

Sin duda alguna, la resolución positiva de la Corte Interamericana de Derechos Humanos sobre las uniones civiles entre personas del mismo sexo representó un efecto de choque en la campaña electoral y encuadró sus límites en torno a este tema. Así, un partido confesional se apropia de la cuestión y obtiene una ganancia política, es decir, logra que la discusión electoral se concentre en ese tema $y$ adquiere una cierta ventaja política electoral entre los sectores de la población sobre los cuales posee alta reputación; es decir, entra al juego político partidista exitosamente. Sin embargo, más allá de si en las elecciones de 2018 se ha construido un dilema entre nuestro Dios y nuestro Diablo por la cuestión del matrimonio entre personas del mismo sexo, lo que resulta claro es que, si bien, por un lado, se ha sufrido el infortunio de tener que enfrentarse a un dilema cuyo efecto principal ha sido definir de manera restringida los parámetros de este proceso electoral, por el otro lado, las razones y motivos para ello, van más allá del conflicto por los derechos humanos y no son necesariamente todos negativos. Dios y el Diablo se vuelven a desencontrar en los tiempos de la transición costarricense hacia la sociedad moderna y secular.

\section{UNA REIVINDICACIÓN SUBJETIVA}

La lectura propuesta aquí es que los participantes en los MRL, incluyendo a personas del cristianismo evangélico y quizás también algunos sectores del catolicismo, poseen características psico-religiosas que les han permitido plantearse ahora una suerte de reivindicación subjetiva proyectada en la sociedad como sistema y en el mundo de la vida (Habermas, 2015), convirtiéndose en actores políticos con un plazo de existencia indeterminado. En el mismo dinamismo, cabe señalar que ha surgido de alguna manera la fantasía de arrebatar a las élites su hegemonía, en particular a 3 élites con las cuales se confrontan de manera explícita 0 implícita: la jerarquía católica, la academia y la izquierda.
Hay pocos estudios nacionales sobre este tema (Solís, 2008; Tapia, Rojas y Villalobos, 2013); sin embargo, los hay realizados fuera del país, en psicología de la religión, ya muy consolidados por cuanto han confirmado hallazgos similares en repetidas ocasiones y perfilan algunas características con las cuales comprender, en una perspectiva psicológica, a los MRL (Saroglou, Christians, Buxant y Casalfiore, 2005; Hayward y Krause, 2014).

Las actividades y características de los MRL no se regulan por un conjunto de normas institucionalizadas controladas más allá del grupo local. Una de sus características diferenciadoras fundamentales consiste en el privilegio concedido, en la expresión religioso-espiritual, a la emocionalidad y al discurso narrativo (Solís, 2008), en lugar de a la racionalidad y al discurso argumentativo. Es cierto que la psicología latinoamericana había identificado este énfasis en lo emocional desde los años 80 (Martín-Baró, 1987 y 1989), cuando aparecen las primeras manifestaciones de este fenómeno psicosocial, sin embargo, la comprensión de sus características se vuelve difícil si el análisis se atiene solo a categorizaciones dicotómicas como la religión del orden versus la religión subversiva u otras similares, las cuales omiten los matices contemporáneos de estas expresiones religiosas (ver el trabajo significativo de Saroglou, Clobert, Cohen, et ál., 2011; Saroglou, 2014). Estos movimientos presentan una serie de características distintivas, las cuales manifiestan un conjunto complejo de tonos grises.

Por ejemplo, la idea según la cual se trata de grupos en los que se manipula a las personas es solo parcialmente verdadera, ya que en realidad acontecen procesos de persuasión similares en otros grupos sociales. Es decir, la manipulación deliberada no es necesariamente la tendencia predominante, sino la persuasión, tal y como ocurre en muchos procesos colectivos. Es cierto, sin embargo, que hay explotadores psicológicos y sociales que se han llegado a asociar con estos grupos. Aún así, podría preguntarse si más, menos o en igual medida que lo reflejan las situaciones recientes de casos de abusos sexuales dentro de la Iglesia Católica. 
Aunque pueda sorprender, la investigación empírica fuera del país muestra que en estos grupos la presencia de trastornos mentales, tal y como los analiza la psicopatología, el psicoanálisis o la psiquiatría, no es más importante que en la población general. Eso sí, la vulnerabilidad relacional es más elevada al inicio de la adhesión y la pertenencia al grupo, la cual suele cambiar con el tiempo, volviéndose el bienestar psicológico general más positivo que negativo entre las personas pertenecientes a los MRL, por ejemplo, en el vínculo a la pareja adulta. El efecto relativamente positivo de la religión sobre el bienestar psicológico y la salud mental, aunque modesto en su magnitud, parece ser estable en el tiempo (Saroglou, Christians, Buxant y Casalfiore, 2005).

Es cierto que el espíritu crítico de los individuos puede verse disminuido en estos grupos, lo cual tiene como efecto un acceso limitado a la autonomía personal. Esto puede provocar que no se cuestione la propia fe, que no haya espacio para la duda $y$, por tanto, que desaparezca la apertura para conocer otros puntos de vista. Aun así, también es cierto que estas características están presentes en grupos no religiosos. De alguna manera, la seguridad ofrecida por el grupo posee como contrapartida la disminución de la autonomía y la amenaza al desarrollo pleno de la persona. Sin embargo, se ha observado que la adhesión a los MRL provoca la disminución de prácticas de riesgo (alcohol, drogas), la búsqueda de sentido de la vida y la disminución de la ansiedad y el estrés (Saroglou, Christians, Buxant y Casalfiore, 2005). Se promueve en ellos un cierto nivel de recuperación de la autoestima, la motivación al logro y, al menos, la fantasía de autosuperación que, según las circunstancias individuales y sociales, podría volverse una superación real apoyada por la teología de la prosperidad.

Estas características psicosociales señalan un contexto que exige ver al otro y pensar en la inclusión de este. En efecto, la vulnerabilidad psicológica y social de las personas que forman parte de los MRL en Costa Rica coincide con la vulnerabilidad de los sectores con un fuerte rezago económico y excluidos de los bienes culturales o del capital cultural, principalmente de la educación. Al parecer, en las elecciones del 2018, ambos grupos podrían ser el mismo: los grupos vulnerables, que en el pasado fueron "capital político" de los otrora partidos tradicionales, hoy son algunas de las comunidades asociadas a los MRL $y$ a algunos otros grupos que se adhieren a un conjunto de valores tradicionales. En ello hay, por una parte, marginación de la dinámica socioeconómica infligida por el Estado $y$, por otro lado, la renuncia de individuos $y$ grupos al mundo social que se vuelve hostil y que los convierte en personas que sufren aquella vulnerabilidad. Esta condición psicosocial podría llegar a considerarse como un estímulo subjetivo que moviliza las energías psíquicas hacia una búsqueda de compensación, generalmente simbólica, y que moviliza también la búsqueda de reconocimiento a un partido político como un actor político pleno. Lo anterior parece cumplir la función de imagen religiosa del mundo ${ }^{3}$.

Las imágenes religiosas del mundo (Habermas, 2006 y 2015) son representaciones o ideas acerca de cómo pensar la realidad. En algunos casos se expresan mediante convicciones, como las de una fe $y$ una visión religiosa del mundo, la cual es, aun así y principalmente, también una experiencia simbólica. En dicha experiencia se crean lazos sociales y son estos lazos, vínculos afectivos. En los movimientos religiosos libres estos vínculos pueden regirse o no por la honestidad, pero, de cualquier manera, crean lazos y redes de cooperación. Sucede aun cuando dichos lazos y redes provienen de

3 A pesar de esta argumentación es posible preguntarse ¿Habrían obtenido los partidos confesionales la misma cantidad de votos si, al inicio de la campaña política de 2018 , no se hubiesen presentado eventos como la resolución de la Corte Interamericana de Derechos Humanos, sobre las uniones civiles del mismo sexo? Cabe mantener la hipótesis (por estudiar), que hubiese sido distinto, pues dicha resolución pudo tener un efecto de cebado o de cebo (de priming), es decir, de atracción profunda de una parte del electorado, la cual fue capitalizada al captar identidades y características psicosociales ligadas a procesos emocionales de decisión de voto. Agradezco al Dr. Carlos Brenes por este interesante comentario. 
la geografía marginada más allá de las puertas imaginarias de San José.

Así pues, los elementos propicios para una movilización, la que dio "carta de ciudadanía" a grupos con una dilatada condición de vulnerabilidad y exclusión, se han manifestado de manera convergente para tratar de conseguir objetivos conforme a convicciones ancladas subjetivamente; sin crítica ni autocrítica.

El dictamen de la Corte Interamericana de Derechos Humanos sobre el matrimonio igualitario aparece como un componente en la superficie, como un distractor. Es quizás una mampara de un dinamismo psico-religioso que ha servido como medio de contraste para evidenciar la reivindicación ante la vulneración socioeconómica y cultural, la cual posee un correlato subjetivo intenso; de ahí la narrativa socioemocional de restauración. La sociedad y la cultura costarricense queda así mejor retratada en sus condiciones reales, en su profunda diversidad.

A las élites le resulta difícil asumir su relación con los MRL. La jerarquía de la Iglesia católica costarricense, cuya autoreferencialidad en el poder le hace difícil ver más allá de sí misma, ha lanzado un manto de indiferencia histórica hacia los MRL y hacia sectores del cristianismo evangélico. En la academia se han construido modelos conceptuales y empíricos con una limitada comprensión de las potencialidades y límites sociales, políticos y culturales de los MRL. La izquierda, probablemente ha justipreciado con equívocos el significado cultural y la capacidad de atracción simbólica y material de dichos movimientos. En conjunto, las élites reflejan un distanciamiento de la lógica y la dinámica de los movimientos religiosos libres.

\section{LA COHESIÓN PSICOSOCIAL Y LA DEMOCRACIA INCITATIVA}

La conformación de la Asamblea Legislativa en la era de la restauración ha mostrado ya una gestión de la gobernanza altamente difícil, sin embargo, no es imposible. Es decir, los nuevos actores políticos representados en los partidos políticos evangélicos han sabido situarse bien respecto a la corrupción y la demagogia, respecto a sus propias rupturas y recomposición como grupo político y, al mismo tiempo, hacen su tarea como opositores, aun cuando deban encarnar las tensiones de la transición hacia la modernidad secular costarricense. La división entre este Dios y este Diablo nacionales ha manifestado un nivel de conflictividad social inédito, en cierta medida provocado por la gestión ambigua de la comunicación política de la misma administración del gobierno Solís Rivera. Es muy probable que la conflictividad social general, antes, durante y después del proceso electoral, halla tenido correlatos relacionales de conflictividad en las familias y en los grupos que sostienen vínculos primarios en todas las clases sociales. La cohesión psicosocial sufre por una nueva amenaza, incluso por la amenaza de los grupos de poder económico. De este modo, la sociedad en la que tengan cabida todas las personas, con una capacidad razonable de gestión del conflicto, parece alejarse un poco más. Esto posee consecuencias de envergadura si se piensa en problemas como el déficit y la reforma fiscal.

La idea que la religión solo podría subsistir en las democracias liberales como un ideal ético de fraternidad (Habermas, 2006 y Simbaña, 2016), vuelve a estar presente. Solo que esta idea no se ha visto del todo confirmada, pues las prácticas religioso-espirituales al transformarse, continúan formando parte del mundo de la vida, incluso en aquellas democracias liberales y laicas más avanzadas; es altamente posible que esta dinámica psicosocial no suceda de manera diferente en la sociedad costarricense. Es tal vez posible dar un lugar a la religión en la esfera pública en una sociedad pluralista, en cuanto la democracia liberal se constituya en una comunidad en la que el diálogo predomine en la resolución de los conflictos (Gauchet, 2004).

En otras palabras, una democracia parlamentaria es un horizonte que parece deseable para canalizar el conflicto y la integración psicosocial. De hecho, la deliberación pública suscitada en torno al contexto electoral, por más precaria que haya sido, ha enriquecido el tejido social de la democracia en el sentido de haber atraído algún tipo de debate. Si bien es cierto, la televisión sigue siendo el medio más frecuentado 
por el electorado para informarse en torno a cuestiones políticas, lo cual deja el uso de las redes sociales en internet en un segundo plano (Alfaro, Alpízar, Cascante y Guzmán, abril de 2018), es también cierto cómo ambos medios han facilitado posicionamientos ideológicos, políticos y socioafectivos más transparentes por parte de personas y grupos. En sí mismos, los conflictos no son un lastre sino una oportunidad a la incitación constructiva.

La posibilidad de gestión del conflicto psicosocial puede ser una práctica, dentro de una democracia, que parlamentaria o no, sea también incitativa (Saroglou, Christians, Buxant y Casalfiore, 2005). En esta, el Estado ocupa un rol activo respecto a la religión y no a la inversa, la religión cumpliendo un rol activo - ¿dominante? - frente al Estado. Significa que las instituciones del Estado asumen el proceso de secularización y modernización, garantizan la libertad religiosa y la tolerancia, así pues, se adelantan e incitan la precaución y la reflexión, buscando la participación de los sectores religiosos por igual. Esto mediante políticas públicas que promuevan la inserción adecuada de los grupos religiosos al juego democrático.

En palabras de Habermas (1999), es la inclusión del otro, bajo una orientación política de la acción social, en el sentido de incluir a todos los participantes en el juego de la deliberación y el diálogo. Así pues, la democracia incitativa incluye considerar a las personas religiosas como actores y no como objetos; implica suscitar dispositivos de cooperación entre diferentes instituciones incluyendo las religiosas que posean ámbitos transversales de acción; motivar a la reflexión cooperativa que se oriente a superar la polémica social entre personas religiosas $y$ no religiosas; estimular la participación abierta de las personas religiosas en procesos sociales y económicos; estimular procesos positivos de aprendizaje cooperativo en grupos y comunidades, religiosas o no. En una política pública responsable, se trata de incitar a los movimientos religiosos libres hacia un proceso social dinámico que los incluya como actores sociales $y$ económicos. En otras palabras, es necesario evitar que los movimientos religiosos libres, como grupos sociales y como individuos, debido a su marginalidad socioeconómica y educativa, se asuman como actores de la renuncia. La renuncia a formar parte de la dinámica social, la renuncia a sus derechos y a su deseo de inclusión psicosocial.

Si bien, una democracia incitativa orientada a los sectores religiosos supone evitar el tratamiento de la religión bajo el mandato, la estigmatización o la coerción, supone a la vez realizar alianzas incitativas de las instituciones democráticas con iglesias, grupos y movimientos religiosos libres en lucha por el reconocimiento (Ricoeur, 2004; Honneth, 1997), como actores políticos, para incitar lo que Gauchet (2004) ha llamado un civismo cristiano. Esto significa proponer una versión del conjunto social conforme a los valores religiosos, pero que sea respetuosa, simultáneamente, del carácter no religioso del conjunto social. Esto se orienta a fortalecer las instancias democráticas y a movilizar la participación dentro de estructuras capaces de favorecer la cohesión psicosocial y lazos sociales que defiendan la cultura de la inclusión del otro. Es un proyecto al cual no podría darse la espalda en una sociedad que en la práctica y pese a la constitución, avanza con espasmos hacia la deseada laicidad.

Habrían 3 conclusiones por extraer a partir de este análisis. En primer lugar, hay una serie de condiciones psicoreligiosas y psicosociales, relacionadas con los movimientos religiosos libres, las cuales convergen en la necesidad de autoexclusión social como instancia débil de afrontamiento de la adversidad psicosocial, lo cual representa un riesgo considerable para las personas participantes en movimientos religiosos libres y para la sociedad en su conjunto. Estas son las condiciones que, solo en parte, podrían haber facilitado el surgimiento de un grupo religioso en la vida política de la sociedad costarricense. En segundo lugar, a partir del surgimiento de ese grupo políticoreligioso, se abre un escenario psicosocial fecundo, a saber, un campo de articulación de políticas incitativas que eviten la autoexclusión, promuevan la negociación y la participación, así como, la inclusión social y cultural. Finalmente, entre las muchas líneas de investigación 
futuras que se desprenden de este análisis, se encuentra la posibilidad de conocer las biografías y establecer en consecuencia las características del desarrollo psicoreligioso de personas que participan de movimientos religiosos libres.

\section{REFERENCIAS}

Alfaro, R.; Alpízar, F.; Cascante, M.J. y Guzmán, J. (enero, 2018). Informe de resultados del estudio de opinión sociopolitica. Centro de Investigación y Estudios Políticos, Universidad de Costa Rica. Recuperado de https://ciep.ucr.ac.cr/ images/InFORMESUOP/EncuestaEnero31/ Informe-encuesta-ENERO-Segundaentrega.pdf

Alfaro, R.; Alpízar, F.; Cascante, M.J. y Guzmán, J. (abril, 2018). Informe de resultados del estudio de opinión sociopolitica. Centro de Investigación y Estudios Políticos, Universidad de Costa Rica. Recuperado de https://ciep.ucr.ac.cr/images/INFORMESUOP/EncuestaAbril2018/Informeencuesta-ABRIL-25.pdf

Alfaro-Redondo, R. y Gómez-Campos, S. (2014). Costa Rica: Elecciones en el contexto político más adverso arrojan la mayor fragmentación partidaria en 60 años. Revista de Ciencia Politica (Santiago), 34(1), 125-144. doi: https://dx.doi. org/10.4067/s0718-090x2014000100006

Alpízar, F. (7 de febrero de 2018). Las costarricas de nuestras mentes. Semanario Universidad. San José, Costa Rica. Recuperado de https://semanariouniversidad.com/pais/las-costarricas-nuestrasmentes/

Armstrong, K. (2004). Los orígenes del fundamentalismo, en el judaísmo, el cristianismo y el islam. Barcelona, España: Tusquets.

Bastian, J. P. (2006). De los protestantismos históricos a los pentecostalismos latinoamericanos: Análisis de una mutación religiosa. Revista de Ciencias Sociales (CI), (16), 38-54.

Beltrán, W. (2009). Secularización: ¿teoría o paradigma? Revista Colombiana de Sociología, 32(1), 61-81.
Bermejo, D. (2013). El «retorno de Dios» en la condición postmoderna, posmetafísica y globalizada. En D. Bermejo (Ed.), ¿Dios a la vista? (pp. 15-82). Madrid, España: Dykinson.

Cortina, A. (2013). El futuro del cristianismo en una sociedad plural. En D. Bermejo (Ed.), ¿Dios a la vista? (pp. 505-520). Madrid, España: Dykinson.

Fuentes, L. (2015). La tibieza de quien peca y reza. Cambios en las creencias religiosas en Costa Rica. San José, Costa Rica: Sebila.

Fuentes, L. (2019). Politización evangélica en Costa Rica en torno a la agenda "provida”: ¿Obra y gracia del Espíritu Santo? Revista Rupturas, 9(1), 85-106.

Gaytán, F. (2018). La invención del espacio político en América Latina: laicidad y secularización en perspectiva. Religião \& Sociedade, 38 (2), 119-147. doi: https://dx.doi. org/10.1590/0100-85872018v38n2cap04

Gauchet, M. (1998). La religion dans la démocratie. Paris, Francia: Folio essais.

Gauchet, M. (2004). Un monde désenchanté? Paris, Francia: l'Atelier y Ouvrières.

Gutiérrez, D. (2010). De las conceptualizaciones de las religiones a las concepciones de las creencias: a manera de introducción. En D. Gutiérrez (Coord.), Religiosidades y creencias contemporáneas: diversidades de lo simbólico en el mundo actual (pp. 9-44). Estado de México, México: El Colegio Mexiquense.

Habermas, J. (1999). La inclusión del otro. Estudios de teoría política. Barcelona, España: Paidós.

Habermas, J. (2006). Religion in public sphere. European Journal of Philosophy, 14, $1-25$.

Habermas, J. (2015). Mundo de la vida, política y religión. Madrid, España: Trotta.

Hayward, R.D. $y$ Krause, N. (2014). Religion and domestic political attitudes around the world. En V. Saroglou (Ed.), Religion, personality and social behaviour. Nueva York, Estados Unidos: Taylor and Francis. Hervieu-Léger, D. y Davie, G. (2010). El despliegue espiritual de los nuevos movimientos 
religiosos. En D. Gutiérrez (Coord.), Religiosidades y creencias contemporáneas: diversidades de lo simbólico en el mundo actual (pp. 215-240). Estado de México, México: El Colegio Mexiquense.

Hervieu-Léger, D. (1999). Le pèlerin et le converti. La religion en mouvement. Paris, Francia: Flammarion.

Honneth, A. (1997). La lucha por el reconocimiento. Barcelona, España: Crítica.

Martín-Baró, I. (1987). Del opio religioso a la fe liberadora. En Montero, M. (Coord.), Psicología política latinoamericana (pp. 229-268). Caracas, Venezuela: Panapo.

Martín-Baró, I. (1989). Sólo Dios salva. Sentido político de la conversión religiosa. Facultad de Ciencias del Hombre y la Naturaleza, Universidad José Simeón Cañas, El Salvador. Inédito.

Murillo, A. (7 de febrero de 2018). Resultado electoral: dos rondas y dos realidades. Semanario Universidad. San José, Costa Rica. Recuperado de https://semanariouniversidad.com/pais/resultado-electoral-dos-rondas-dos-realidades/

Pignataro, A. y Cascante, M. J. (2017). Los electorados de la democracia costarricense: percepciones ciudadanas y participación en torno a las elecciones nacionales de 2014. San José, Costa Rica: Tribunal Supremo de Elecciones, Instituto de Formación y Estudios en Democracia.

Programa Estado de la Nación en Desarrollo Humano Sostenible (2017). Estado de la educación (Informe nro. 6). San José, Costa Rica: Consejo Nacional de Rectores. Recuperado de http://www. estadonacion.or.cr/educacion $2017 /$ informe-para-descarga.html

Raventós, C.; Fournier, M.; Fernández, D. y Alfaro, R. (2012). Respuestas ciudadanas ante el malestar con la política: salida, voz y lealtad. San José, Costa Rica: Tribunal Supremo de Elecciones, Instituto de Formación y Estudios de la Democracia Universidad de Costa Rica, Centro de Investigaciones y Estudios Políticos.

Ricoeur, P. (2004). Parcours de la reconnaissance. Trois études. Paris, Francia: Stock.

Saroglou, V.; Clobert, M.; Cohen, A.B.; Ladd,
K.L.; Van Pachterbeke, M.; Adamovova, L.; Blogowska, J.; Brandt, P-Y.; Çukur, C.S.; Hwang, K.K.; Johnson, K.A.; Miglietta, A.; Stefanidi, F.M.; MuñozGarcía, A.; Murken, S.; Roccas, S.; Roussiaux, N. y Tapia-Valladares, J. (2011). Believing, Bonding, Behaving, and Belonging: The cognitive, emotional, moral, and social dimensions of religiosity and their psychological characteristics across religions and cultures. Journal of Cross-Cultural Psychology XX (x), 1-21.

Saroglou, V. (Ed.) (2014). Religion, personality and social behaviour. Nueva York, Estados Unidos: Taylor and Francis.

Saroglou, V.; Christians, L.L.; Buxant, C. y Casalfiore, S. (2005). Mouvements religieux contestés. Psychologie, droit et politiques de précaution. Problèmes actuels concernant la cohésion sociale. Gante, Bélgica: Academia Press.

Simbaña, R. (2016). La religión en la esfera pública: Habermas y el resurgimiento de la religión. Religación, 1, 1-17.

Solís, M. (2008). Microsociología de la interacción y constitución del sí mismo en la vivencia comunitaria neopentecostal. Actualidades en Psicología, 22, 19-42.

Tapia, J. (2019). Biopoética de la adolescencia. Identidades, creencias, vínculos. San José, Costa Rica: EuCR.

Tapia, J.; Rojas, M. y Villalobos, M. (2013). Configuraciones del fundamentalismo religioso entre jóvenes universitarios de Costa Rica: perspectiva psicosocial. Revista de Ciencias Sociales, 139, (1), 115-135.

Treminio, I. (2018). Costa Rica: nuevos actores y transformación del paisaje político. En M. Alcántara; D. Buquet y M.L. Tagina (Eds.), Elecciones y partidos en América Latina en el cambio de ciclo (pp. 161-176). Madrid, España: Centro de Investigaciones Sociológicas.

Fecha de ingreso: 21/03/2019

Fecha de aprobación: 29/08/2019 